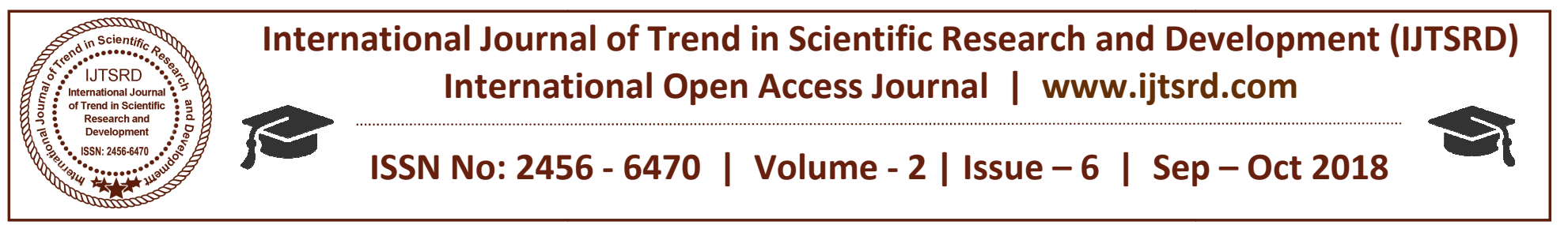

\title{
Crowd Sensing Systems: A Mini Review
}

\author{
W. A. F. W. Othman, S. S. N. Alhady, A. A. A. Wahab, M. H. A. Ahmad \\ School of Electrical \& Electronic Engineering, \\ Universiti Sains Malaysia, Nibong Tebal, Penang, Malaysia
}

\begin{abstract}
The main purpose of crowd sensing systems is to extract information based on the crowd in environment. . This paper briefly explains each type of sensors that were widely used in real life situations. Each type of sensors is covered from basic understanding, tools, method of algorithm, their finding, way of conducting test, and results. Such as visual sensor, acoustic sensor, capacitive, infrared, radio-frequency identification and carbon dioxide gas sensors. The review focused on existing system used on human occupancy. The goal is to summarize the existing approach from various types, guides the creation of new systems and point toward future research directions.
\end{abstract}

Keyword: Crowd sensing, human occupancy and carbon dioxide sensor.

\section{INTRODUCTION}

Crowd sensing system focuses on creating, an environment that is basically being aware of human present which further response in particular area of applications. The information gather can be identified, for example the number of person in a room. Such an adequate system is potentially capable performing human detection starting from the lowest level real time data mining all the way into much challenging data scale depending on limitation of the sensor itself. Nowadays, the need to sense human is far more important as ever before because it can be implemented in various applications, either simple or sophisticated applications.

The implementation of crowd sensing makes direct use of simple application, for instance alarm signal where as any human passes by on the sensor [21], ventilation system for indoor air quality based on human occupancy, infant monitoring [12], and surveillance systems based on human behaviour [16]. Other works are focusing on detecting, counting or estimating human present, tracking them, and possibly differentiate between human and nonhuman subjects [20].

Going even further, this data mining from sensors can be gathered by computing approach, either by individual or group of people which depends on the limitations of a particular sensor and user application in order to make a higher level decision. Every sensor has its own drawback that must be considered. This review concludes a variety of creative solution based on multiple sensors development from many researchers that will reveal the progress that have been made before in each direction. So, this will lead us into a new opportunity of creativity.

The scope of this paper provides general view and aspect of consideration while developing crowd sensors based on well defined 6 types of sensor. For instance, visual sensor, acoustic sensor, capacitive, infrared, radio frequency and carbon dioxide (CO2) gas sensors. These sensors operate according to their own traits. Such as, intrinsic traits from human scent, weight, wave reflectivity, voice, human motion, vibration and body heat. Extrinsic trait is a trait from environment properties such as wearable radio frequency identification (RFID) tag.

\section{OVERVIEW}

The approaches reviewed research works were based on crowd sensing system for years, one can see in Fig.1. In overall, $56 \%$ research papers are within 5 years. It covers from $42 \% \mathrm{CO} 2$ gas based detector and $14 \%$ on other types. Then, $44 \%$ covered for all research papers before 2009, 34\% focuses on CO2 sensor and $10 \%$ for the rest of other sensors. 


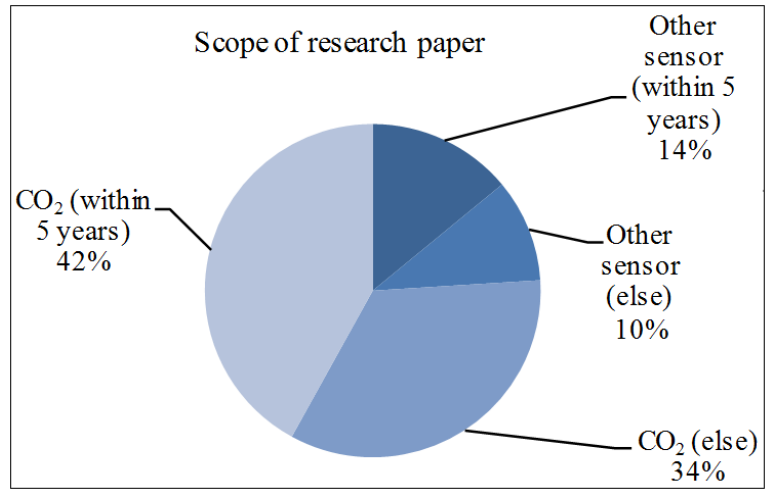

Fig. 1: Research breakdown

\section{TYPE OF SENSORS}

\subsection{Acoustic sensor}

Sabatier et al. [40] Introduces passive and active ultrasonic sensors, generating from footstep acoustic and Doppler signatures as human detection and potentially differentiate with other moving non human object. Ultrasonic sensor is sensitive with sliding contacts sound.

The active method utilizes continuous wave ultrasonic Doppler sonar involves transmission of electromagnetic waves to the human body and registration of the backscattered waves by the radar. Melanie B. Rudoy et al. [20] stated, active ultrasound sensor transmitting continuous $40 \mathrm{kHz}$ tone then returned as Doppler shift signal, due to natural swaying torso velocity and swinging limbs while walking. TV-VAR is a correlations process of both independent signal with $95 \%$ accuracy differentiate between human and dog [20].

Both sensors address provide information of fundamental frequency and harmonic [3]. Thyagaraju Damarla et al combined ultrasonic, acoustic and seismic sensors for border crossing. Data were fused together using Dempster-Shafer fusion paradigm. Only 6 targets can be identified instead of 7 [45].

Fusion features is the key for detection with high percentage of correct modalities. Presenting algorithm on estimating subject in covered area really shows the potential by applying with multiple subjects depending on position and limitation of people.

\subsection{Image sensor}

Danny B. Yang et al installed 8 image sensors network in order to overcome the limited resolution and blockage of object. Simple processing on image and lightweight algorithm are needed to run in real time, very effective of estimating people in crowded in small room but cost increase linearly with the number of camera as the processing time also increase [10].

Rahmalan et al. estimating crowd density monitoring visual system in outdoor scenes by using 3 different techniques of estimating crowd as a comparison among them. Then categorized into a range of density via Self Organizing Map (SOM) with minor problems exist, shadow and misrecognition of surface floor. Silhouette visual camera might not be as advanced as visual camera [31].

Maria Andersson et al. addresses Hidden Markov Model (HMM) detection algorithm as automatic classification of only human behaviour tracking for surveillance camera. Data from two visual cameras as head detectors and one thermal infrared camera (TIR) rough pose estimation were collected. TIR camera is emitted radiation sensitive and useful in darkness but it still has risk such as false alarm [16].

Mikel Rodriguez et al. improved occlusions, movements, varying density and misleading body parts appearance. It builds with a tracking-bydetection framework without initialization. Visual cameras can detect human presence and track with more than 100 people in crowded scene but still have more potential. [23].

\subsection{Radio Frequency sensor}

Patwari and Wilson discussed on considerable future works of radio frequency (RF) sensor networks without carrying radio tag instead only based on changes happen in channel by using multiple path propagation from ultra-wideband measurement, MIMO, deploy RF sensor around building, received signal strength and polarization [26].

It provides high accuracy compared with single path for estimating people via device free localization (DFL). DFL passive RFID does not need tag in Wagner and Timmermann (2013). RFID reader antennas are placed directly behind the high mounted passive transponder lines that were placed around measurement area [4].

But it needs lots of sensor data that leads to high localization result and computation time. So, clustering algorithm compensates this system tradeoff between measurement speed and localization precision. 


\subsection{Infrared sensor}

Chowdhury et al. developed pyro-electric in response with thermal radiation, warm body causes a positive differential change and when leaves, reverse happen. It is a commercial alarm triggering with low cost, power and wider field of view with common issue due to false alarm [8].

\subsection{Capacitive sensor}

Miika Valtonen et al. developed passive indoor of human tracking based on low frequency electric field approach by measuring the capacitance between multiple floor tiles and receiving electrode. Accuracy tests were conducted based on the standing and walking variations. Error probability distribution test seems to have a little exponentially decreasing with the error distance increases. It still needs improvement in human posture and walking accuracy despite this module is cheap and everlasting [21].

\subsection{Carbon dioxide sensor}

\section{A. Characteristic}

Leephakpreeda et al. introduces the occupancy-based demand control ventilation (DCV) based on $\mathrm{CO} 2$ level measurements while entering and leaving the place. $\mathrm{CO} 2$ sensors were placed at indoor (return) air and outdoor (supply) air. Estimation can be obtained if $\mathrm{CO} 2$ generation rate of the occupants per person closely represent the constant actual activities such as seated or walking [44].

S. T. Taylor addresses $\mathrm{CO} 2$ is bio-effluents generated their size, age, fitness, and activity level, nearly proportional to occupant and their activity level. The room $\mathrm{CO} 2$ is at the $\mathrm{CO} 2$ max and a minimum output signal at the ambient conditions (400 ppm). Single zone system is simpler rather multiple detached room test model [39].

S. Costanzo et al. stated people breathe out $\mathrm{CO} 2$ depending on their activity level and used as indicator for room's occupancy level. Possible natural ventilation rates range from 3.38 until $7.17 \mathrm{~L} / \mathrm{s}$ per person. $\mathrm{CO} 2$ sensors can be featured as an energy saving [35].

P. Stavova et al. shows build up period when people are sleeping during night time and decay period which is after the occupant left the room. $\mathrm{CO} 2$ production is dependent on metabolic rate based on human activity level. Measured equipments were placed at 4 different places with 1.1 meter height. No effect of furnishing based on $\mathrm{CO} 2$ distribution. Only constant level of activity was selected [28].

\section{B. Atmosphere distribution}

Marianah Masrie et al. developed IR absorption gas sensor along with humidity and RTD temperature sensors. It consists of light signals emitted from the LED with modulation frequency. As the $\mathrm{CO} 2$ level increases, the intensity of light reaching the detector decreases due to gas absorption. CO range was constant at $0.2 \mathrm{ppm}$. Avoid noise from sunlight and inducing noise from internal circuitry [17].

Non-invasive $\mathrm{CO} 2$ monitoring system reduces the risk of Sudden Infant Death Syndrome among infant according to Hung Cao et al. Metal-oxide based carbon dioxide sensors (Figaro TGS4161) are placed around the crib. It has unidentically repeatable concentration. Placing more sensors and enhanced calibration might be an improvement [12].

Halgamuge et al. Suggested indoor $\mathrm{CO} 2$ levels in between 400-2000 ppm while outdoor are 350-450 ppm High indoor CO2 levels causing drowsy, and headache at lower activity levels. $\mathrm{CO} 2$ sensor requires a warm-up period and protected from rain, wind and heat radiation. Sensors were placed at desk height. Once the students entered, it increased to $600-800$ ppm in 80 min. $\mathrm{CO} 2$ levels can increase if window and door are kept closed. Overall, room size and number of occupancy need to be considered [15].

Average $\mathrm{CO} 2$ generation rate from minimum activity level is $0.31 \mathrm{~L} / \mathrm{min}$ per person according from Dougan and Damiano. Range of operation, drift issues and calibration is needed. The preferred locations for sensors are in multiple placed. Avoiding doors, windows or close to occupants. Rate of $\mathrm{CO} 2$ production against human metabolic activity is directly proportional [11].

Mikola and Koiv provide $\mathrm{CO} 2$ level during summer period varied from 340 to $3200 \mathrm{ppm}$. Meanwhile, winter period varied from 370 to $4000 \mathrm{ppm}$. Then air tightness in room might affect the $\mathrm{CO} 2$ level with tighter air flow holds more concentration. Temperature difference can be seen during a long period with small effect [2].

Tint and Trauman stated the parameters of indoor climate were measured with TESTO 435. Outdoor $\mathrm{CO} 2$ concentration does affect the indoor air quality 
(IAQ) because of indoor air was provided from the outside air. State of window showed small different values [27].

Simone Steiger et al. measured $\mathrm{CO} 2$ distribution at various vertical axis and horizontal axis position. $\mathrm{CO} 2$ gas accumulates at the ceiling rather at the floor. $\mathrm{CO} 2$ is mixed with warm breathing air, it turns upwards with it. $\mathrm{CO} 2$ accumulate at height between $1.2-2.3 \mathrm{~m}$ above room floor with small variation and does not uniformly distributed. The differences of measured $\mathrm{CO} 2$ dispersion grew up to $75 \%$ when the doors were opened. CO2 level measured in $\mathrm{kg} / \mathrm{m}^{3}$ and then converted into ppm (parts per million). Sensor positions placed away from openings [42].

Marzuki Ismail et al. provides sampling IAQ parameters for every $5 \mathrm{~min}$ using data analyzer. data were analyzed by using single classification analysis of variance (ANOVA) F test. Result shows significant difference $(\mathrm{P}<0.05)$ between the means of all 3 schools in Kuala Terengganu. Malaysia is located in the tropical region with a hot and humid climate, which affected thermal comfort levels of the students. temperature profile increase slightly from morning to afternoon as humidity is reversed [19].

Mumma provides test to accurately predict real-time occupancy, with 45 students are involved. The set point is not constant; it decreases from $1,000 \mathrm{ppm}$ in full occupancy condition then went to $600 \mathrm{ppm}$ when only five people are present. actual occupancy estimated within two people error count [38].

C. C. Chang and Z.F.Yang used non-dispersive infrared (NDIR) sensors; It consists of an infrared source with a determined frequency, an optical cavity where the gas to be detected. The $\mathrm{CO} 2$ level at $600-$ $1000 \mathrm{ppm}$ will make uncomfortable condition [7]. People may feel sleepy at 1000-2500 ppm. LED will turn to red when $\mathrm{CO} 2$ level is over $2500 \mathrm{ppm}$. The designing wireless sensing system based on ZigBee technology for monitoring of ventilation in the car space. Open window reduce the density of $\mathrm{CO} 2$.

Luther and Atkinson seek to justify more accurate calculation method based upon the amount of people, their activity and room size should be more carefully considered. The $\mathrm{CO} 2$ levels become high during occupied periods. Door opening reduced (halved) $\mathrm{CO} 2$ levels while increasing the air exchange rate over $300 \%$. Humidity has small influences based on occupancy level in certain place range from 55- $66 \%$. The entrance or source where the air exchanges between indoor and outdoor in room effect the $\mathrm{CO} 2$ level with $50 \%$ reduction [18].

Nassif provide an alternative CO2-based demand control ventilation strategy. The most possible scenario is where number of people varies and no accurate information is needed. They able to estimate actual occupancy profiles $100 \%, 75 \%$ and $50 \%$. It is hard to estimate accurately the actual number of occupants in each zone unless occupancy sensor located in each zone but too costly and may not ensure a perfect estimation [25].

Sean Meyn et al. stated multiple data source are significantly more informative. variability of $\mathrm{CO} 2$ levels with the actual occupancy are high due to fluctuations in ambient $\mathrm{CO} 2$ levels. $\mathrm{CO} 2$ sensors suffer from poor response time (about 10-20 minutes) due to delay between occupancy level increases and build up of $\mathrm{CO} 2$ concentration. Their approach reduced average occupancy estimation errors to $11 \%$. Decentralized algorithms should be applied [41].

\section{Related properties}

D.I. Shin et al. focuses on centralized monitoring by using web based network rather than individually manage for each incubator. The accuracy of these sensors influenced by the circuit, and error introduced by A/D converter. It can be done by proper correction algorithm in a micro-controller. Room temperature showed constant change with $80-90 \%$ relative humidity $(\mathrm{RH})$, due does not rely on the occupancy [9].

Van Den Bossche et al. stated humidity is not dependent on occupants with just about $6 \%-7 \%$ of average humidity when air is heated up to room temperature. $\mathrm{CO} 2$ sensors are expensive and have bigger drift than humidity sensors. $\mathrm{CO} 2$ is a good indicator for occupied rooms where smoking is not allowed [47].

Metal-oxide $\mathrm{CO} 2$ and humidity sensors are mounted around crib in S. Aruna and P. Sushma Chowdary. The sensitivity, selectivity and humidity dependence were tested. Humidity sensor need to be considered [37].

Melikov et al. proposes the effect of elevated facial air velocity under different temperature and humidity. Collected data were analyzed using Shapiro-Wilk's W 
and ANOVA tests. Nose dryness does not effect on humidity or air movement. Air movement does effect on human eye dryness especially at $30 \%$ RH. Eye irritation effected in high humidity and air movement condition [1].

Prasad et al. CO2 sensor (TGS4161) need to expose with atmospheric level of 350ppm for 10 minutes. Output is linear in semi-log scale. O2 sensor (KE-25) provides a linear output voltage signal relative to percentage of oxygen. Both sensors are resistive heating and consume a lot of energy. $\mathrm{CO} 2$ sensor has short life (6 to 9 months). But data compression modeling algorithms helps in saving the energy of node. Temperature and humidity sensors must be considered for accurate readings [32].

Stock investigates $\mathrm{CO}$ exposures among boaters, with $734 \mathrm{ppm}$ (outside) compared with $80 \mathrm{ppm}$ (inside cabin). $\mathrm{CO}$ is colorless, odorless, tasteless gas produced by incomplete burning of carbon containing materials such as gasoline or propane fuel. $\mathrm{CO}$ is 35 ppm for full exposure, with a ceiling limit of $200 \mathrm{ppm}$ [43].

Raatikainen et al. provides $\mathrm{CO} 2$ curves and distributions in hourly average. Volatile organic compounds (VOCs) are chemicals compound from thinners, gasoline-powered machinery, paints, building materials, cleaning chemicals and cigarette smoke. The data were analyzed with Matlab-software platform. CO2 level indicates less than $750 \mathrm{ppm}$ most of the time. TVOC concentrations indicating less than 5 ppm in both study schools [22].

Wendt et al. recommends maintaining indoor $\mathrm{RH}$ levels between $30-50 \%$. If too low, bacterial populations tend to flourish, thus contributing to respiratory infections. If too high, will resulting fungal growth. Occupant activities will raise $\mathrm{RH}$. The range of indoor relative humidity is in between 40 $60 \%$ unsignificantly different neither open nor closed window. $\mathrm{CO} 2$ continuously increased during the highoccupancy period at Crush Load End (high occupancy). Longer decay time is associated with a tighter construction. $\mathrm{CO} 2$ decay after test. As the CO2level increases, Oxygen (O2) percentage decreases at the same time [49].

K. Galatsis et al. shows exhaust pollutant contributed headaches, nausea, dizziness, eyes irritation and breathing process. As the $\mathrm{CO}$ increase, $\mathrm{O} 2$ also decrease just like between $\mathrm{CO} 2$ and $\mathrm{O} 2$ gases. But $\mathrm{CO}$ gas is more dangerous than $\mathrm{CO} 2$. $\mathrm{CO}$ can significantly reduce the $\mathrm{O} 2$ values compared with $\mathrm{CO} 2$ even faster [13].

Schulte et al. stated low RH impacts on occupant but it is not treat. 1 to $3 \mathrm{ppm}$ of $\mathrm{CO}$ concentration was generally rare. It can be observed at chemistry laboratories and classrooms near city traffic. False $\mathrm{CO}$ readings occurred with the present of Odor and Gases $(\mathrm{O} \& \mathrm{G})$ signal, activated by non-CO substances from food preparation in cafeterias, whiteboard markers, and dry hand washing stations [34].

Kobayashi et al. address the combination of scent sensors and accelerometers. 3 gas sensors; air contaminants sensor (TGS2602) for cigarette smoke, and cooking scents, methane sensor (TGS2611) for gas leak, and $\mathrm{CO} 2$ sensor. Accuracy of context recognition without accelerometer shows 0.74 of accuracy. Decision tree has been built by using J48 algorithm. The combination of multiple gas scent sensor could creating characteristic of certain situation such as person is in toilet or smoking [14].

Rice stated confined spaces offer risk for adverse effects from the displacement of $\mathrm{O} 2$ by $\mathrm{CO} 2$ gases. High-level $\mathrm{CO} 2$ exposure and low-level $\mathrm{O} 2$ causes headaches, poor memory and concentrate ability, sleeping difficulty, double vision, photophobia, loss of eye movement and personality changes. Low-level $\mathrm{CO} 2$ exposure $(<3 \%)$ produce short term effects in healthy [33].

S. Costanzo et al. counted actual number of occupants by measured $\mathrm{CO} 2$ levels to compute the occupancy via Meckler equation, assuming the production of $\mathrm{CO} 2$ equal to $0.0045 \mathrm{l} / \mathrm{s}$ per person. $\mathrm{CO} 2$ levels start to rise and continued until the number of people levels off [36].

$\mathrm{CO} 2$ sensors require time before detecting $\mathrm{CO} 2$ buildup. Erickson and Cerpa proposes Markov Chain (MC) model, describe on how the state of a system and room occupancies of a building change over time. It would be possible to implement occupancy based on heating, ventilation, and air conditioning controls strategies [46].

Embedded wireless sensor system presented in Boonsawat et al. by using Star Topology network. LM335A is used as temperature sensor. The Arduino 
Analog Input pin (as A/D converted into digital value in the range $0-1023$, where 0 represents $0 \mathrm{~V}$ and 1023 represents $5 \mathrm{~V}$ ) was read in volts. 4 sensor nodes were deployed far away from each other, 10-30 meters. All data can be stored into the MySQL Database and retrieved later for analysis [6].

\section{Algorithm integration}

Dong and Andrews implements algorithms for sensor based modelling the objective is to find best from these 4 HVAC set point schedules. The environmental sensors network was used for the model of occupancy behavioural patterns. behavioural model are determined using the minimum description length (MDL) criteria and periodicity (PD). Semi-Markov model allows for duration in each state before transitioning to the next state. Overall, the fusion environmental gas sensors will resulting data collection from various variables that needed to be analyzing with a suitable algorithm [5].

Zheng Yang et al. proposes back propagation (BP) artificial neural network (ANN), in estimating the number of occupants. In 3 hidden layers, estimation accuracy is $91.75 \%$ compared with single layer, $90.82 \%$. Each variable has 13 weights, indicate its influence. Sound, door status and temperature have the lowest priority. Humidity, motion and $\mathrm{CO} 2$ level are the most influential variables in estimating occupancy. Temperature has low priority and humidity is less influenced by HVAC system. Proposed system can estimate occupant $62.41 \%$ of the time [50].

Fuzzy based simulation model system has been developed in Karunakaran et al. It operates with IFTHEN rules that define the system behaviour. Fuzzy logic controller (FLC) design utilized multi input and multi output parameters. Membership functions range with minimum and maximum levels within 3002100ppm, simulated by using Matlab-Simulink environment. FLC maintained the $\mathrm{CO} 2$ level within the permissible limits through the control action given to the supply air fan [30].

Jaradat \& Al-Nimr aims to provide Multiple Input Single Output control (MISO) system. Fuzzy logic provides a non-mathematical model. Four distributed sensors assumed to be low at first. Then, people are entered the room and perform some activates. Based on output FLC, it was able provides $7 \%$ energy saving [24].
Qi Zheng et al. provides the Fuzzy Delphi-Analytic Hierarchy Process (FD-AHP) method and weights were assigned. Then, evaluation scores and grades were designed using the Weber-Fechner Law. They estimate the priority (weight) in order, organic pollutants $>$ inorganic pollutants $>$ bio pollutants. Organic materials have more influence regarding indoor air quality such as VOC along with $\mathrm{CO} 2$ level [29].

Wafa Batayneh et al. stated FLC provides linguistic variables in words rather than numbers to map input space. Capacitive humidity sensor provides linear capacitance change compared with resistive. Humidity and temperature measurement need to fused. Evacuation fan works at highest capacities and the $\mathrm{AC}$ and dehumidifier are turned off, if the humidity, temperature and odour are high. The relationships between inputs and outputs are selected based on user expert information. Simulated scenarios show the effectiveness of the proposed system [48].

\section{DISCUSSION}

Every sensor is briefly explained in term of their basic understanding as well as their application. Finding alternative method other than visual image and acoustic sensor is the reason and its contribution in real life that can be applied in future work on crowd sensing system.

Later, this review paper can help other researchers pursuing their work. $\mathrm{CO} 2$ gas based sensor is primary focus and interest area. Understanding its effect in human presence, and identifying its surrounding or environment properties that might have influence the capability, performance of $\mathrm{CO} 2$ sensor and its drawback seems to be the main concerns. Other type of sensor only covers small portion of review that will provide knowledge on how they work. The introduction of $\mathrm{CO} 2$ gas sensor in crowd sensing system is expected to continue to grow. Their efficiency and cost effective will be expanded.

In term of $\mathrm{CO} 2$ gas sensor application, $92 \%$ of the works are based on occupancy based ventilation system or for indoor air quality (IAQ) in closed room (Fig.2). Another $8 \%$ focuses on infant monitoring system. $\mathrm{CO} 2$ gas sensor needed to combine with other related properties in crowd detection, temperature, humidity, $\mathrm{O} 2$ and $\mathrm{CO}$ sensors. Overall reading shows all these research papers are less concentrating on providing further extensive test, less focuses on 
accuracy of and just use these sensor properties as indirect information for certain application.

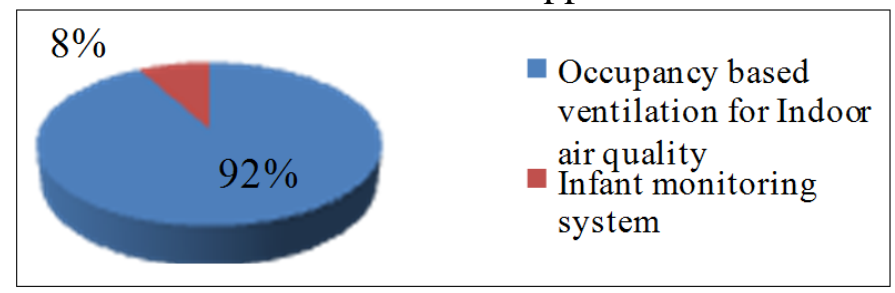

Fig. 2: Carbon dioxide sensor application

\section{CONCLUSION}

Above section provides viewer basic knowledge based on important element in each different sensor, their objective, tools, methods and results that can be used later on. Small portions of review regarding image, acoustic, radio frequency, infrared and capacitive sensors are included. Meanwhile, vast majority review papers are based on $\mathrm{CO} 2$ gas sensor is included that leads to a view where this experiment is heading next in term of human crowd detection. Overall, $\mathrm{CO} 2$ sensor seem less accurate, low response time and tends to has more trade-off component compared with other type but it can be fitted in its way and still be informative.

\section{ACKNOWLEDGEMENTS}

The authors would like to thank the Universiti Sains Malaysia for partly supported the work by Fundamental Research Grant of MoE Malaysia (Grant number: USM/PELECT/6071239).

\section{REFERENCES}

1. A. Melikov, Jan Kaczmarczyk, and D. Silva. "Impact of air movement on perceived air quality at different level of Relative humidity." Proceedings of the 11th international conference on indoor air quality and climate-indoor air, Denmark, August 2008. pp. 17-22.

2. A. Mikola, and T. A. Koiv. "Indoor Air Quality in Apartment Buildings of Estonia." In Computers and simulation in modern science: selected papers from WSEAS conferences V, 2011. pp. 257-261.

3. Alexander Ekimov, and James M. Sabatier. "Human detection range by active Doppler and passive ultrasonic." SPIE Defense and Security Symposium. International Society for Optics and Photonics, 2008. pp. 69430R-69430R.

4. Benjamin Wagner, and Dirk Timmermann. "Adaptive clustering for device free user positioning utilizing passive RFID." Proceedings of the 2013 ACM conference on Pervasive and ubiquitous computing adjunct publication. ACM, 2013. pp. 499-508.

5. Bing Dong and Burton Andrews. "Sensor-Based Occupancy Behavioral Pattern Recognition For Energy \& Comfort Management in Intelligent Buildings." Eleventh International IBPSA Conference, Scotland, July 2009. pp. 1444-1451.

6. Boonsawat, Vongsagon, Jurarat Ekchamanonta, Kulwadee Bumrungkhet, and Somsak Kittipiyakul. "XBee Wireless Sensor Networks for Temperature." In the Proceedings of the 2010 2nd ECTI-Conference on Application Research and Development.Thailand, 2010. pp. 1-6.

7. Chia-Chi Chang, and Zeng-Feng Yang. "A HighPrecision NDIR CO2 Sensing Module for ZigBee Applications." Proceedings of International Conference on Advanced Information Technologies, April 2013. pp. 27-1 - 27-4.

8. Chowdhury, Zamshed Iqbal, Masudul Haider Imtiaz, Muhammad Moinul Azam, Mst Rumana Aktar Sumi, and Nafisa Shahera Nur. "Design and Implementation of Pyroelectric Infrared Sensor Based Security System Using Microcontroller." In Students' Technology Symposium (TechSym), 2011 IEEE, 2011.pp. 1 - 5.

9. D. I. Shin, S. J. Huh \& T. S. Lee. "Web-based remote monitoring of infant incubators in the ICU." International journal of medical informatics, 71(2), 2003. pp. 151-156.

10. Danny B. Yang, Hector H. Gonzalez and Leonidas J. Guibas. "Counting People in Crowds with a Real-Time Network of Simple Image Sensors." In Computer Vision, 2003. Proceedings. Ninth IEEE International Conference, 2003. pp. 122 - 129.

11. David S. Dougan, and L. Damiano. "CO2 Based Demand Control Ventilation (DCV). Do Risks Outweigh Potential Rewards?" ASHRAE journal 46, 2004. pp. 47 - 53.

12. Hung Cao, Lun-Chen Hsu, Thermpon Ativanichayaphong, Jeongsik Sin, and J.C. Chiao. "A non-invasive and remote infant monitoring system using CO2 sensors." Sensors, IEEE, 2007. pp. 989 - 992.

13. K. Galatsis, W. Wlodarski, Y. X. Li, and K. Kalantar-Zadeh. "Vehicle cabin air quality monitor using gas sensor for improved safety." Optoelectronic and Microelectronic Materials and Devices, 2000. Proceedings Conference on. IEEE, 
International Journal of Trend in Scientific Research and Development (IJTSRD) ISSN: 2456-6470

2000. pp. 65-68.

14. Kobayashi, Yasuki, Tsutomu Terada, and Masahiko Tsukamoto. "A Context Aware System Based on Scent." Japan: Wearable Computers (ISWC), 2011 15th Annual International Symposium on. IEEE, 2011. pp. 47 - 50.

15. M. N. Halgamuge, T. K. Chan and P. Mendis. "Ventilation Efficiency and Carbon Dioxide Concentration." PIERS Online, 2009. pp.637 640.

16. Maria Andersson, Joakim Rydell and Jörgen Ahlberg. "Estimation of Crowd Behavior Using Sensor Networks." 12th International Conference on Information Fusion. In Information Fusion, 2009. 12th International Conference on IEEE, 2009. pp. 396 - 403.

17. Marianah Masrie, Ramli Adnan and Anuar Ahmad. "A Hybrid Gas Sensor based on Infrared Absorption for Indoor Air Quality Monitoring." Proceedings of the World Congress on Engineering 2, 2012. pp. 1-5.

18. Mark B. Luther and Steven E. Atkinson. "Measurement and solutions to thermal comfort, $\mathrm{CO} 2$ and ventilation rates in schools." In Healthy Buildings 2012: Proceedings of the 10th International Conference of Healthy Buildings, 2012. pp. 1-6.

19. Marzuki Ismail, Nur Zafirah Mohd Sofian, and Ahmad Makmon Abdullah. "Indoor Air Quality in Selected Samples of Primary Schools in Kuala Terengganu, Malaysia." The international journal published by the Thai Society of Higher Education Institutes on Environment, Malaysia, 2010. pp. 103-108.

20. Melanie B. Rudoy, Charles E. Rohrs, and Jingdong Chen. "Signatures of Walking Humans from Passive and Active Acoustic Data using Time-Varying Vector Auto regressions." Signals, Systems and Computers, 2007. ACSSC 2007. Conference Record of the Forty-First Asilomar Conference on. IEEE, 2007. pp. 2253 - 2256.

21. Miika Valtonen, Jaakko Mäentaust and Jukka Vanhala. "Tile Track: Capacitive Human Tracking Using Floor Tiles." PerCom 2009. IEEE International Conference on. IEEE, 2009. pp. 1 10.

22. Mika Raatikainen, Jukka-Pekka Skön, Mari Turunen, Kauko Leiviskä, and Mikko
Kolehmainen. "Evaluating Effects of Indoor Air Quality in School Buildings and Students' Health: A Study in Ten Schools of Kuopio, Finland." 2nd International Conference on Environment, Energy and Biotechnology, Singapore, 51(16), 2013. pp. 80-86.

23. Mikel Rodriguez, Ivan Laptev, Josef Sivic, and JY. Audibert. "Density-aware person detection and tracking in crowds." In Computer Vision (ICCV), 2011 IEEE International Conference, 2011. pp. 2423-2430.

24. Mohammad Abdel Kareem Jaradat, \& Moh'd A. Al-Nimr. "Fuzzy Logic Controller Deployed for Indoor Air Quality Control in Naturally Ventilated Environments." Journal of Electrical Engineering, 60(1), 2009. pp. $12-17$.

25. Nassif, N. " CO2 -Based Demand-Controlled Ventilation Control Strategies for Multi-Zone HVAC Systems." Proceedings of the Eleventh International Conference Enhanced Building Operations, New York City, October 2011. pp. 18.

26. Neal Patwari, and Joey Wilson. "RF Sensor Networks for Device-Free Localization: Measurements, Models and Algorithms." Proceedings of the IEEE 98(11), 2010. pp. 1961 1973.

27. P. Tint and A. Trauman. "Health risk assessment in atrium type buildings." International Journal of "Energy \& Environment, 6, 2012. pp. 389-396.

28. P. Stavova, A. K. Meliko, J. Sundell and K. G. Neydenov. "A new approach ventilation measurement in home based on $\mathrm{CO} 2$ produced by people." International Centre for Indoor Environment and Energy, Denmark, 2007. Pp.1-6.

29. Qi Zheng, Dong Hoon Lee, Jeong Tai Kim, \& Sun Kuk Kim. "A health performance evaluation model of apartment building indoor air quality." Indoor and Built Environment 20(1), May 2010. pp. 26-35.

30. R. Karunakaran, R. Parameshwaran, A. Senthilkumar, and S. Iniyan. "Improving IAQ and Energy Efficiency for Building Using Variable Air Volume (VAV) Air Conditioning System Based On Fuzzy Logic." Conference on Indoor Air Quality, Ventilation \& Energy Conservation (IAQVEC) in Buildings, Japan, October 2007. pp. 1-10.

31. Rahmalan, Hidayah, Mark S. Nixon, and John N. 
International Journal of Trend in Scientific Research and Development (IJTSRD) ISSN: 2456-6470

Carter. "On crowd density estimation for surveillance." In Crime and Security, 2006. The Institution of Engineering and Technology Conference on IET, 2006. pp. 540 - 545.

32. Raja Vara Prasad, Mirza Sami Baig and Rahul K. Mishra. "Real Time Wireless Air Pollution Monitoring System." ICTACT Journal on Communication Technology, 2011. Pp.1-6.

33. Rice, Susan A. "Human Heath Risk Assessment of CO2: Survivors of Acute High-Level Exposure and Populations Sensitive to Prolonged LowLevel Exposure." Environments, 3(5), May 2004. pp. 7-15.

34. Robert Schulte, Barry Bridges, and David Grimsrud. "Continuous IAQ Monitoring." ASHRAE Journal, 47(5), 2005. pp. 38-46.

35. S. Costanzo, A. Cusumano and C. Giaconia. "Ventilation problems in heritage buildings." Proc. 2nd IASME/WSEAS International Conference on Energy and Environment (EE'07), Portoroz, Slovenia. 2007. pp. 279-284.

36. S. Costanzo, A. Cusumano, C. Giaconia, and P. Valdiserri. "Experimental determination of natural air ventilation rates based on $\mathrm{CO} 2$ concentration." In Proceedings of the 4th IASME/WSEAS international conference on Energy \& environment, 2009. pp 383-387.

37. S. Aruna, and P. Sushma Chowdary. "Infant Monitoring System." International Journal of Computer Science and Communication, 2011. pp. 501-503.

38. S. Mumma. "Transient Occupancy Ventilation by monitoring CO2." ASHRAE IAQ Applications, USA, 2004. pp. 21-23.

39. S. T. Taylor. "CO2 -Based DCV Using 62.12004." ASHRAE Journal 48(5), 2006. pp. 67 - 73.

40. Sabatier, James M., and Alexander E. Ekimov. "Ultrasonic Method for Human Motion Detection." Mississippi Univercity National Center for Physical Acoustic, 2006. pp. 1-30.

41. Sean Meyn, Amit Surana, Yiqing Lin, Stella M. Oggianu, Satish Narayanan and Thomas A. Frewen. "A sensor-utility-network method for estimation of occupancy in buildings."
Proceedings of the 48th IEEE Conference, 2009. pp. 1494-1500.

42. Simone Steiger, Runa Tabea Hellwig, and Elmar Junker. "Distribution of carbon dioxide in a naturally ventilated room with high internal heat load." Nordic Symposium on Building Physics, 2008. pp. 1-8.

43. Stock, Allison. "Centers for Disease Control and Prevention." Department of Health and Human Services, 2002. Pp.1-14.

44. $\mathrm{T}$ Leephakpreeda, $\mathrm{R}$ Thitipatanapong and $\mathrm{T}$ Grittiyachot,. "Occupancy-Based Control of Indoor Air Ventilation: A Theoretical and Experimental Study." Science Asia 27(4), 2001. pp. 279-284.

45. Thyagaraju Damarla, Asif Mehmood \& James Sabatier. "Detection of people and animals using non-imaging." 14th International Conference On Information Fusion, 2011.pp. 1 - 8.

46. V. Erickson and A. Cerpa. "Occupancy Based Demand Response HVAC Control Strategy." In BuildSys, USA, 2010. pp. 1-6.

47. Van Den Bossche, Nathan, Arnold Janssens, N. Heijmans, and P. Wouters. "Performance Evaluation of Humidity-Controlled Ventilation Strategies in Residential Buildings." ASHRAE, 2007. pp. 1-9.

48. Wafa Batayneh, Omar Al-Araidah, \& Khaled Bataineh. "Fuzzy logic approach to provide safe and comfortable indoor environment." International Journal of Engineering, Science and Technology, Jordan 2(7), 2010. pp. 65-72.

49. Wendt, R., H. Aglan, S. Livengood, M. Khan, and E. Ibrahim. "Indoor air quality of an energyefficient, healthy house with mechanically induced fresh air." Transaction American Society of Heating Refregerating and Air Conditioning Engineers, 110(2), 2004. pp. 77-84.

50. Zheng Yang, Nan Li, Burcin Becerik-Gerber, and Michael Orosz. "A Non-Intrusive Occupancy Monitoring System for Demand Driven HVAC Operations." Construction Research Congress, USA, 2012. pp. 828-837. 